Check for updates

Department of Pediatrics, Ann and Robert H Lurie Children's Hospital, Feinberg School of Medicine, Northwestern University, USA

2 Aga Khan University, Pakistan

3 London School of Hygiene and Tropical Medicine, London, UK Correspondence to: M Arshad

Cite this as: BMJ 2020;371:m4501 http://dx.doi.org/10.1136/bmj.m4501 Published: 24 November 2020

\title{
Covid -19, misinformation, and antimicrobial resistance
}

\author{
Stop misinformation about antibiotics for covid $\mathbf{- 1 9}$, or resistance will rise \\ Mehreen Arshad, ${ }^{1,2}$ Syed Faisal Mahmood, ${ }^{2}$ Mishal Khan, ${ }^{2,3}$ Rumina Hasan ${ }^{2,3}$
}

Well before covid-19, the world already faced an emergent threat of antimicrobial resistance, and many have sounded the alarm over further escalation during the pandemic. ${ }^{1}$ A study from the US, for example, showed that $71 \%$ of covid-19 patients received antibiotics while only $4 \%$ had true bacterial coinfection. ${ }^{2}$ This overuse of antibiotics may have contributed to the observed $10 \%$ increase in resistance against several classes of antibiotics (compared with 2019) at the same institution.

Spread of misinformation during epidemics has been documented before, ${ }^{3}$ but covid-19 has brought with it a global deluge of misinformation. Politicisation of the pandemic in many countries led to politicians being a leading source of misinformation, ${ }^{4}$ while initial underestimation of the pandemic by key public health stakeholders led to inconsistent messaging and widespread public confusion. ${ }^{5} \mathrm{~A}$ survey of online news articles identified incorrect reports published in 25 languages in 87 countries, roughly a fifth of which were on cure and treatment. ${ }^{6}$ In low and middle income countries, many of which already have a high burden of multidrug resistant organisms, misinformation includes overemphasis on the role of antimicrobials. This includes the use of azithromycin, which has been shown repeatedly to have no efficacy against covid-19. ${ }^{7}$

Lack of basic knowledge on infections and their treatment has resulted in poor understanding of this viral pandemic and its aetiology by general populations worldwide and, in some settings, medical professionals. ${ }^{8}$ In Australia, $44 \%$ of respondents to a population survey incorrectly thought antibiotics could treat or prevent covid-19, ${ }^{9}$ and university students in Jordan who believed in conspiracy theories around covid-19 also tended to incorrectly identify antibiotics as curative. ${ }^{10}$

\section{Better communication}

The cornerstone of covid-19 management remains supportive. As a "second wave" emerges and concerns rise, a strategy offering only symptom management in outpatient settings may cause further anxiety. This can often be mitigated by open and honest communication. Unfortunately, overburdened clinicians dealing with a surge in patient numbers have limited time to spend on individual encounters, particularly in low and middle income countries. Many have received inadequate training in patient communication, further impairing education of patients and the public. ${ }^{11}$

Misinformation affects clinicians and health policy makers as well as the public-partly fuelled by management controversies triggered by the early release of poorly reported and preliminary research findings. Early posting of preprints has allowed rapid dissemination of important research but also raised concerns over the public release of poorly conducted studies and the premature or inaccurate media reporting of unsubstantiated findings that often follows. ${ }^{12}$ Both policy makers and frontline clinicians struggle to keep up with rapidly evolving evidence on the management of covid-19, particularly clinicians in low and middle income countries with limited access to timely, verified sources of information.

Strategies must be developed now to counter the detrimental effect of misinformation on the use of antimicrobials and prevent further deterioration in the global crisis in antimicrobial resistance. Since roughly half the adults in emerging economies ${ }^{13}$ and almost all adults in higher income countries have access to a digital device, and more than half the world's population uses social media, ${ }^{14}$ these strategies must include creative, regulated online media campaigns to combat misinformation.

Some organizations such as the World Health Organization and Nigeria Centre for Disease Control, ${ }^{15}{ }^{16}$ already use their digital platforms to correct antimicrobial misinformation by discussing the ineffectiveness of antimicrobials as a primary treatment for covid-19. Others, including the Africa Centres for Disease Control and Prevention and the US National Institutes of Health and Centers for Disease Control and Prevention, ${ }^{17-19}$ provide general information on public health measures, disease symptoms, associated myths, and stigma but do not discuss antimicrobial use specifically. They should be encouraged to correct this serious omission.

Concerted effort is also required to make sure medical providers have rapid, timely access to evidence updates on the management of all aspects of covid-19. Online teaching, webinars on management algorithms, systematic reviews, and living guidelines such as The BMJ's Rapid Recommendations, ${ }^{20}$ should be developed by regional and global agencies, and made available free to healthcare workers, allowing the rapid dissemination of trustworthy evidence.

Fragile healthcare systems in many parts of the world may not withstand the covid-19 pandemic if also faced with a substantial increase in antimicrobial resistance. We must tackle the twin pandemics of covid-19 and misinformation simultaneously.

Competing interests: The BM/has judged that there are no disqualifying financial ties to commercial companies. The authors declare no other interests. The BMI policy on financial interests is here: https://www.bmj.com/sites/default/files/attachments/resources/2016/03/16-current-bmj-education-coi-form.pdf."

Provenance and peer review: Not commissioned; externally peer reviewed. 
1 Hsu J. How covid-19 is accelerating the threat of antimicrobial resistance. BM/2020;369:m1983. doi: 10.1136/bmj.m1983 pmid: 32423901

2 Nori P, Cowman K, Chen V, etal. Bacterial and fungal coinfections in COVID-19 patients hospitalized during the New York City pandemic surge. Infect Control Hosp Epidemiol 2020:1-5. doi: 10.1017/ice.2020.368 pmid: 32703320

3 Sell TK, Hosangadi D, Trotochaud M. Misinformation and the US Ebola communication crisis: analyzing the veracity and content of social media messages related to a fear-inducing infectious disease outbreak. BMC Public Health 2020;20:550. doi: 10.1186/s12889-020-08697-3 pmid: 32375715

4 Gonsalves G, Yamey G. Political interference in public health science during covid-19. BMJ 2020;371:m3878. doi: 10.1136/bmj.m3878 pmid: 33023874

5 Wang Y, Hao H, Platt LS. Examining risk and crisis communications of government agencies and stakeholders during early-stages of covid-19 on Twitter. Comput Human Behav2021;114:106568. doi: 10.1016/j.chb.2020.106568 pmid: 32982038

6 Islam MS, Sarkar T, Khan SH, etal. Covid-19-related infodemic and its impact on public health: a global social media analysis. Am J Trop Med Hyg 2020;103:1621-9. doi: 10.4269/ajtmh.20-0812 pmid: 32783794

7 Azad A. Antimicrobial crisis. DAWN2020 Sep 8. https://www.dawn.com/news/1578514.

8 Shehadeh M, Suaifan G, Darwish RM, Wazaify M, Zaru L, Alja'fari S. Knowledge, attitudes and behavior regarding antibiotics use and misuse among adults in the community of Jordan. A pilot study. Saudi Pharm /2012;20:125-33. doi: 10.1016/j.jsps.2011.11.005 pmid: 23960783

9 Thomas R, etal. Examining Australian's beliefs, misconceptions, and sources of information for COVID-19: a national online survey.medRxiv, 2020:2020.07.27.20163204. [Preprint.] doi: 10.1101/2020.07.27.20163204

10 Sallam M, Dababseh D, Yaseen A, etal. Conspiracy beliefs are associated with lower knowledge and higher anxiety levels regarding covid-19 among students at the University of Jordan. Int J Environ Res Public Health 2020;17:E4915. doi: 10.3390/ijerph17144915 pmid: 32650409

11 Khan MS, Bory S, Rego S, etal. Is enhancing the professionalism of healthcare providers critical to tackling antimicrobial resistance in low- and middle-income countries? Hum Resour Health 2020;18:10. doi: 10.1186/s12960-020-0452-7 pmid: 32046723

12 Glasziou PP, Sanders S, Hoffmann T. Waste in covid-19 research. BMJ 2020;369:m1847.pmid: 32398241

13 Poushter J.Smartphone ownership and internet usage continues to climb in emerging economies. Pew Research Centre, 2016. https://www.pewresearch.org/global/2016/02/22/smartphoneownership-and-internet-usage-continues-to-climb-in-emerging-economies/. 2016.

14 DATAREPORTAL. Digital 2020: July global statshot. 2020. https://datareportal.com/reports/digital2020-july-global-statshot.

15 Nigeria CDC. Take responsibility campaign. https://youtu.be/G-wB_IANUzw

16 WHO. Coronavirus disease (COVID-19) advice for the public: mythbusters. https://www.who.int/emergencies/diseases/novel-coronavirus-2019/advice-for-public/mythbusters\#antibiotics

17 Africa CDC. Covid-19 social media support kit. https://africacdc.org/download/covid-19-socialmedia-support-kit/.

18 US CDC. Social media toolkit, updated 9 Nov 2020. https://www.cdc.gov/coronavirus/2019ncov/communication/social-media-toolkit.html.

19 NIH. Covid-19 social media resources. https://www.nih.gov/news-events/covid-19-social-mediaresources.

20 Lamontagne F, Agoritsas T, Macdonald H, etal. A living WHO guideline on drugs for covid-19. BMJ 2020;370:m3379. doi: 10.1136/bmj.m3379 pmid: 32887691

This article is made freely available for use in accordance with BMJ's website terms and conditions for the duration of the covid-19 pandemic or until otherwise determined by BMJ. You may use, download and print the article for any lawful, non-commercial purpose (including text and data mining) provided that all copyright notices and trade marks are retained. 